Meta

Journal des traducteurs

Translators' Journal

\title{
La traduction au croisement des frontières : de la terminologie à l'idéologie
}

\section{Chirine Chamsine}

Volume 60, numéro 2, août 2015

$60^{\mathrm{e}}$ anniversaire. Les horizons de la traduction : retour vers le futur $60^{\text {th }}$ Anniversary. Translation's Horizons: Back to the Future

60mo aniversario. Los horizontes de la traducción: regreso al futuro

URI : https://id.erudit.org/iderudit/1032869ar

DOI : https://doi.org/10.7202/1032869ar

Aller au sommaire du numéro

Éditeur(s)

Les Presses de l’Université de Montréal

ISSN

0026-0452 (imprimé)

1492-1421 (numérique)

Découvrir la revue

Citer ce document

Chamsine, C. (2015). La traduction au croisement des frontières : de la terminologie à l'idéologie. Meta, 60(2), 318-318.

https://doi.org/10.7202/1032869ar d'utilisation que vous pouvez consulter en ligne. 


\title{
La traduction au croisement des frontières: de la terminologie à l'idéologie
}

\author{
Chirine Chamsine \\ Université de Montréal, Montréal, Canada \\ chirine.chamsine@umontreal.ca
}

Une simple lecture des événements politiques qui ont fait la une des médias à l'échelle internationale au cours des dernières années nous montre que l'affrontement aujourd'hui se manifeste entre des idéologies et des visions différentes du monde. Par conséquent, les conflits eux aussi sont différents et la lutte devient avant tout idéologique. Dans ce contexte, les mots deviennent des armes et l'enjeu est double: car, d'un côté, les mots ont une histoire et de l'autre côté, ils font l'histoire. Si ce constat peut s'appliquer à toutes les langues, nous nous intéressons particulièrement dans le présent développement à la langue arabe au contact des langues occidentales, notamment le français. L'une des particularités du monde arabe, qui domine actuellement le paysage géopolitique, est l'inscription de son idéologie dans un système culturel où la religion joue un rôle primordial. C'est pourquoi à l'époque où ces conflits s'internationalisent, on assiste à un intérêt croissant orienté vers l'islam, souvent indissociable de la notion d'arabité en Occident.

Le rapport entre langue arabe, culture et religion constitue un véritable défi à l'heure actuelle où l'arabe subit des phénomènes de «décontextualisation » et de « resémantisation » en imprégnant d'autres langues. La présente étude s'intéresse à l'ancrage culturel du vocabulaire politique arabe et aux enjeux traductologiques de la traversée terminologique et idéologique d'une langue-culture vers une autre, en évoquant les questions suivantes: Peut-on définir l'objet culturel et délimiter le champ d'intraduisibilité ou de résistance? Quels sont les procédés linguistiques choisis par le traducteur pour établir un équilibre communicationnel? Quelles en sont les conséquences pour la reconstruction idéologique du lecteur occidental ? Comment la stéréotypie et la stigmatisation influencent-elles la réception de la traduction dans la culture d'accueil en créant des amalgames et des malentendus?

Dans ce contexte particulier et au lendemain des "révolutions arabes» et des grandes mutations socioculturelles, aussi bien dans le monde arabe qu'en Occident, la traduction réussira-t-elle à devenir «la langue du monde» et à créer un espace commun de communication et de compréhension?

Chirine Chamsine est titulaire d'un doctorat en traductologie de l'Université de Caen BasseNormandie, France (2011). Elle a été attachée temporaire d'enseignement et de recherche à l'Université Stendhal Grenoble 3 (2012-2013). Elle est actuellement responsable des cours d'arabe à l'Université de Montréal et chargée de cours à l'Université du Québec à Montréal. Ses travaux de recherche portent sur la problématique de la traduction-médiation et les rapports entre langues, représentations et cultures. Elle s'intéresse également à l'analyse terminologique et traductologique du discours politique arabe, ainsi qu'à l'évolution sémantique des termes et expressions spécialisés et leur passage d'une langue-culture à une autre. 